REFERENCES

Bellanti, J. A. (1968). American fournal of Diseases of Children, 115, 239.

Bellanti, J. A., Buescher, E. L., Brandt, W. E., Dangerfield, H. G., and Crozier, D. (1967). Fournal of Immunology, 98, 171.

Bienenstock, J., and Tomasi, T. B. (1968). Fournal of Clinical Investigation, 47,1162 .

Chodirker, W. B., and Tomasi, T. B. (1963). Science, 142, 1080

Crabbé, P. A., and Heremans, J. F. (1966). Gut, 7, 119.

Pollak, V. E., Gaizutis, M., and Rezaian, J. (1968). Fournal of Laboratory and Clinical Medicine, $71,338$.

Rossen, R. D., Alford, R. H., Butler, W. T., and Vannier, W. E. (1966) fournal of Immunology, 97, 369.

Rossen, R. D., Morgan, C., Hsu, K. C., Butler, W. T., and Rose, H. M (1968). Fournal of Immunology, 100, 706.
Shevsky, M. C., and Stafford, D. D. (1923). Archives of Internal Medicine, 32, 222.

South, M. A., Cooper, M. D., Wollheim, F. A., and Good, R. A. (1968). American fournal of Medicine, 44, 168.

Tomasi, T. B. (1969). Arthritis and Rheumatism, 12, 45.

Tomasi, T. B., Tan, E. M., Solomon, A., and Prendergast, R. A. (1965). fournal of Experimental Medicine, 121, 101.

Fournal of Experimental Medicine, 121, 101 .
Tomasi, T. B., and Zigelbaum, S. (1963). Fournal of Clinical Investigation, 42, 1552 .

42, 1552 .
Tourville, D., Bienenstock, J., and Tomasi, T. B. (1968). Proceedings of the Society of Experimental Biology and Medicine, 128, 722 .

Uehling, D. T., and Stiehm, E. R. (1969). Abstract IX International Congress of Nephrology, p 359. Stockholm.

Uehling, D. T., Wilhemy, M., and Stiehm, E. R. (1970). In press.

\title{
Response of Asthmatics to Isoprenaline and Salbutamol Aerosols Administered by Intermittent Positive-pressure Ventilation
}

\author{
Y. F. J. CHOO-KANG, ${ }^{*}$ M.B., B.SC., M.R.C.P.ED. ; SHEENA S. PARKER, $†$ M.B., CH.B. \\ I. W. B. GRANT, $\ddagger$ M.B., F.R.C.P.ED.
}

\begin{abstract}
Summary: The bronchodilator and cardiac effects $\checkmark$ produced by aerosols of $0.5 \%$ isoprenaline and of $0.25,0.5$, and $1 \%$ salbutamol administered in $40 \%$ oxygen by intermittent positive-pressure ventilation were compared in 24 asthmatic patients. Isoprenaline and salbutamol in concentrations of $0.5 \%$ were equipotent in peak bronchodilator effect; salbutamol was superior in total bronchodilator effect and duration of average effect, but the peak bronchodilator effect occurred earlier after isoprenaline. Significantly greater tachycardia was produced by $0.5 \%$ isoprenaline than by the same concentration of salbutamol. The $0.25,0.5$, and $1 \%$ concentrations of salbutamol had about the same peak bronchodilator effect, but there was a stepwise increase in total effect and duration of average effect in relation to the concentration used. A similar stepwise increase in heart rate was also noted, but with all concentrations this was significantly less than with $0.5 \%$ isoprenaline. It was concluded that a $0.5 \%$ solution of salbutamol, which provided maximal bronchodilatation without important tachycardia, was therapeutically superior to the other three treatments.
\end{abstract}

\section{Introduction}

The $\beta$-adrenergic stimulant isoprenaline administered by inhalation as an aerosol has until recently been used more often than any other sympathomimetic amine in the treatment of bronchial asthma. It has the disadvantage of producing undesirable cardiovascular side effects, and this has prompted search for an equally effective bronchodilator drug with a less pronounced action on the myocardium. Orciprenaline has proved disappointing in this respect because it is only slightly less prone than isoprenaline to increase the heart rate and blood pressure (Kennedy and Simpson, 1969). Another isoprenaline derivative, salbutamol, the pharmacological properties of which were first described by Hartley et al. (1968), is as effective a bronchodilator as isoprenaline and has a longer duration of action. It does not produce cardiovascular side effects when inhaled in the recommended dose (Choo-Kang et al., 1969; Kennedy and Simpson, 1969), but when administered in larger doses by

\footnotetext{
- Medical Registrar.

+ Senior House Officer.

Consultant Physician.

piratory Diseases Unit, Northern General Hospital, Edinburgh, and

Department of Respiratory Diseases, University of Edinburgh.
}

inhalation (Riding et al., 1969), orally (Kennedy and Simpson, 1969), or intravenously (Warrell et al., 1970) it has been shown to produce a slight increase in heart rate. Nevertheless, it is now being prescribed on a large scale in the treatment of bronchial asthma.

Because patients with access to bronchodilator aerosols are apt to exceed the recommended dosage, even when sternly warned not to do so, clearly it is important to determine whether salbutamol is less dangerous than isoprenaline when administered in large doses, particularly in conditions of hypoxia, such as exist in patients with status asthmaticus, in whom serious toxic effects are probably more likely to occur. When planning a study of this type it is important in the first instance, for reasons of safety, not to expose patients simultaneously to the possible dangers of high dosage and hypoxia. An evaluation of relative toxicity must also take into consideration the degree of benefit derived from the treatment given. This paper reports the first stage of such an investigation, in which we have compared in asthmatic patients without significant hypoxia the degree of bronchodilatation and tachycardia produced by salbutamol and isoprenaline administered by inhalation in the form of an aerosol. In the second stage, which will be reported in a later communication, hypoxic patients with status asthmaticus are being given a salbutamol aerosol by inhalation in a dose which has been shown in the first stage to produce the most favourable balance between bronchodilation and tachycardia.

One of the main problems in a study of this type, as Warrell et al. (1970) have pointed out, is to devise a reproducible technique for the inhalation of bronchodilator aerosols which will ensure that when a comparison is made between two drugs or between various doses of the same drug any difference observed is specifically related to these two variables. When pressurized dispensers are used it is unlikely that the whole of the prescribed dose ever reaches the bronchi. This in itself is not important, but, because there is a "hit or miss" element in the use of pressurized dispensers, the proportion of each dose reaching the bronchi must vary widely, and this will tend to blur differences between the effects of one drug and another, and between the effects of various doses of the same drug. In an attempt to resolve this problem it was decided in this study to administer nebulized diluted solutions of the drugs by intermittent positive-pressure ventilation (IPPV) for a period of three minutes, using a Bennett ventilator to deliver the aerosol to the patient through a tightly fitting facemask. With this technique it is of course not possible to measure the volume of solution which lodges in the bronchi, as some of the inhaled aerosol is sub- 
sequently exhaled, but it can reasonably be assumed that this volume is about the same in every case, as none of the aerosol can escape into the atmosphere during inspiration (as it often does when pressurized dispensers are used), and a three-minute period of continuous inhalation is likely to provide a more consistent intake of aerosol than a single inhalation from a pressurized dispenser.

As it was considered that isoprenaline and salbutamol were equipotent bronchodilators-an impression later confirmed by the work of Warrell et al. (1970)-it was decided to make a direct comparison between the effects of these two drugs by giving each of them as a $0.5 \%$ aerosol in normal saline by IPPV. Identical studies were carried out on the same group of patients with $0.25 \%$ and $1 \%$ solutions of salbutamol, in an attempt to determine the lowest concentration of this drug which would produce maximum bronchodilation, and to compare the effect of the three concentrations of salbutamol on heart rate.

\section{Plan of Trial}

Twenty-four patients were studied. Each of them received for periods of three minutes on consecutive days aerosols of isoprenaline and salbutamol in $40 \%$ oxygen delivered by IPPV from a Bennett ventilator in the following concentrations: isoprenaline $0.5 \%$, salbutamol $0.25,0.5$, and $1 \%$.

The drug was nebulized during each inspiratory cycle. The mean volume nebulized was $2 \mathrm{ml}$, with a range of 1.2 to $3.6 \mathrm{ml}$. In individual patients the range was less wide, seldom exceeding $0.5 \mathrm{ml}$. Because the proportion of the nebulized volume retained in the bronchi was not known, it was possible to measure only the upper limit of the dose, which was as follows: isoprenaline $(0.5 \%), 10 \mathrm{mg}$; salbutamol $(0.25 \%)$, $5 \mathrm{mg}$; salbutamol $(0.5 \%), 10 \mathrm{mg}$; and salbutamol $(1 \%)$, $20 \mathrm{mg}$.

Every patient received each of the four treatments on one of four consecutive days, except in eight cases, where the duration of the study was extended to six days to suit the patients' convenience. The sequence of treatment regimen was randomized. The identity of the drug and its concentration were unknown both to the patient and to the technician who made the observations. Forced expiratory volume in one second $\left(\mathrm{FEV}_{1}\right)$ was measured 10,5 , and 1 minute before treatment, and at 5,15,30,60,120,180, and 240 minutes after treatment. The $\mathrm{FEV}_{1}$ was measured with a Gaensler spirometer; three recordings were made at each observation, and the highest was selected for analysis. Forced vital capacity (FVC) and $\mathrm{FEV}_{1} / \mathrm{FVC}$ ratio were also measured, but in the light of previous experience (Choo-Kang et al., 1969) it was decided to restrict the statistical observations to changes in $\mathrm{FEV}_{1}$. Immediately before each series of $\mathrm{FEV}_{1}$ recordings the heart rate was read from a Hewlett Packard cardiac monitor, using light disposable stick-on chest electrodes. During nebulization of the drug, and for the next 60 minutes, the electrocardiograph was closely observed for cardiac arrhythmias.

Six additional patients satisfying the same criteria as the original 24 patients were observed in the same way, but were given normal saline solution instead of a bronchodilator drug. The object of this part of the study was to determine the effect of IPPV itself on $\mathrm{FEV}_{1}$ and heart rate.

\section{Patients Studied and Method of Analysis}

The 24 patients included in the main study consisted of 11 men and 13 women aged 14 to 80 (mean 51) years. All had chronic asthma, for which they were receiving long-term, daily, or intermittent corticosteroid therapy, with the exception of two who were taking only bronchodilator drugs. The daily dose of corticosteroids, in terms of prednisoared from 2.5 to 10 (mean 7.8) mg. Patients who had in corticosteroids intermittently took their usual dose every day throughout the period of the trial. Every patient was known to have responded well in the past to bronchodilator drugs given by inhalation.

The mean $\mathrm{FEV}_{1}$ of the 24 patients was $1,551 \mathrm{ml}$., with a range of 410 to $3,533 \mathrm{ml}$. The mean figure was $71.8 \%$ of the mean value for the patients' known maximum $F E V_{1}$, with a range of 41 to $86 \%$.

The $\mathrm{FEV}_{1}$ and heart rate were plotted graphically against time. The maximum increase was designated peak effect. The time taken to attain peak effect was regarded as an index of the rapidity of action of the drug. The area under the curve was used to express total effect. By dividing the area under the curve (total effect) by the peak effect, the duration of average effect was calculated. The four treatments were then compared in these terms for both $\mathrm{FEV}_{1}$ and heart rate.

\section{Results}

\section{FEV 1}

The changes in $\mathrm{FEV}_{1}$ in terms of peak effect, time to peak effect, total effect, and duration of average effect after each treatment are given in Table I. The mean pretreatment FEV varied from 1,478 to $1,601 \mathrm{ml}$. between the four treatments. The level of pretreatment $\mathrm{FEV}_{1}$ influenced the subsequent form of the response/duration curve, and over the range of results in this trial an increase of $100 \mathrm{ml}$. in the pretreatment $\mathrm{FEV}_{1}$ caused the peak effect to be $62 \mathrm{ml}$. lower, the time to peak effect to be six minutes earlier, the total effect to be 15 1. minute lower, and the duration of average effect to be five minutes shorter. In order that the changes of $\mathrm{FEV}_{1}$ after each treatment might be more comparable all the indices derived from the response/duration curves have been adjusted in Table I to show what each value would have been if all the pretreatment values had been $1,551 \mathrm{ml}$. (the mean of all the pretreatment values).

Peak Effect.-There was no significant difference between the mean peak effect with the four treatments used, suggesting that the dose of isoprenaline and the three doses of salbutamol were virtually equipotent in this respect. Scrutiny of the peak effect achieved by individual patients with each treatment showed that after at least one of the four treatments 21 of the 24 patients reached or surpassed the highest $\mathrm{FEV}_{1}$ they had reached during the previous 12 months. In the other three cases the deficiency amounted to 225,120 , and $150 \mathrm{ml}$. Maximum or near-maximum bronchodilation was thus achieved by at least one of the four treatments in almost every case. The highest individual peak effect was recorded by three patients after $0.5 \%$ isoprenaline, by seven patients after $0.25 \%$ salbutamol, by six patients after $0.5 \%$ salbutamol, and by eight patients after $1 \%$ salbutamol.

Time to Peak Effect.-The time to peak effect for $0.5 \%$ isoprenaline was significantly shorter $(\mathrm{P}<0.05)$ than that for any of the salbutamol concentrations, but there was no significant difference in this respect between these concentrations.

Total Effect.-The total effect on $\mathrm{FEV}_{1}$ of $0.5 \%$ isoprenaline was significantly less than that of the lowest concentration of salbutamol $(\mathrm{P}<0.05)$. The total effect of each salbutamol treatment was significantly different $(P<0.05)$ higher concentrations produced greater total effect.

TABLE I.-Changes in FEV 1 in terms of peak effect, time to peak effect, total effect, and duration of average effect after each treatment

\begin{tabular}{|c|c|c|c|c|c|}
\hline Treatment & $\begin{array}{c}\text { Mean } \\
\text { Pretreatment }^{\text {FEV }} \text { (ml.) }\end{array}$ & 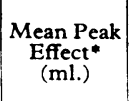 & $\begin{array}{l}\text { Mean Time } \\
\text { to Peak } \\
\text { Effect* } \\
\text { (min.) }\end{array}$ & $\begin{array}{c}\text { Total } \\
\text { Effect* } \\
\text { (1./min.) }\end{array}$ & $\begin{array}{c}\text { Duration } \\
\text { of Average } \\
\text { Effect } \\
\text { (min.) }\end{array}$ \\
\hline $\begin{array}{ll}0.25 \% & \text { salbutamol } \\
0.5 \% & \text { salbutamol } \\
1 \% \% & \text { salbutamol } \\
0.5 \% & \text { isoprenaline }\end{array}$ & $\begin{array}{l}1,601 \\
1,478 \\
1,556 \\
1,569\end{array}$ & $\begin{array}{l}643 \\
638 \\
691 \\
669\end{array}$ & $\begin{array}{l}86 \\
93 \\
88 \\
47\end{array}$ & $\begin{array}{r}114 \\
120 \\
141 \\
91\end{array}$ & $\begin{array}{l}169 \\
186 \\
195 \\
135\end{array}$ \\
\hline
\end{tabular}

-Adjusted to allow for differences in pretreatment values between the four groups. 
Duration of Average Effect.-The duration of average effect on $\cdot \mathrm{FEV}_{1}$ after $0.5 \%$ isoprenaline was significantly shorter than that of the lowest concentration of salbutamol $(P<0.05)$. The duration of average effect on $\mathrm{FEV}_{1}$ after each salbutamol treatment was significantly related to the dose used $(P<0.05)$-higher concentrations produced longer duration of average effect.

Taking the above observations together, it would appear that isoprenaline $(0.5 \%)$ and all concentrations of salbutamol $(0.25,0.5$, and $1 \%)$ had similar peak bronchodilator effects; but isoprenaline, because of its much shorter duration of action, had a significantly smaller total effect and duration of average effect $(P<0.05)$. The total effect and duration of average effect were significantly related to the concentration of salbutamol $(\mathbf{P}<0.05)$.

\section{Heart Rate}

The changes in heart rate in terms of peak effect, time to peak effect, total effect, and duration of average effect after each treatment are given in Table II. After all four treat-

TABLE II.-Changes in heart rate in terms of peak effect, time to peak effect, total effect, and duration of average effect after each treatment

\begin{tabular}{c|c|c|c|c|c}
\hline Treatment & $\begin{array}{c}\text { Mean } \\
\text { Pretreatment } \\
\text { Heart Rate/ } \\
\text { min. }\end{array}$ & $\begin{array}{c}\text { Mean Peak } \\
\text { Effect } \\
\text { (beats/min.) }\end{array}$ & $\begin{array}{c}\text { Mean Time } \\
\text { to Peak } \\
\text { Effect } \\
\text { (min.) }\end{array}$ & $\begin{array}{c}\text { Total } \\
\text { Effect } \\
\text { (beats/min.) }\end{array}$ & $\begin{array}{c}\text { Duration } \\
\text { of } \\
\text { Average } \\
\text { Efect } \\
\text { (min.) }\end{array}$ \\
\hline $0.25 \%$ salbutamol & 79 & 5 & 22 & 231 & 29 \\
$0.5 \% \%$ salbutamol & 80 & 9 & 25 & 376 & 36 \\
$1 \% \%$ salbutamol & 83 & 13 & 34 & 862 & 50 \\
$0.5 \%$ isoprenaline & 80 & 29 & 7 & 966 & 26 \\
\hline
\end{tabular}

ments the heart rate returned to pretreatment level within two hours and the changes in heart rate were analysed only for this period. The pretreatment heart rates for the four treatment groups were similar in value, and as the small variation in the mean value did not affect the form of the response/duration curves no adjustments were necessary as for FEV .

Peak Effect.-The mean peak increase in heart rate with $0.5 \%$ isoprenaline during the first hour was 29 per minute, while that with $0.25,0.5$, and $1 \%$ salbutamol was 5,9 , and 13 per minute, respectively. The peak effect with $0.5 \%$ salbutamol was significantly less than with the same concentration of isoprenaline $(P<0.05)$. The peak effect was also significantly related to the dose of salbutamol $(P<0.05)$ and showed a stepwise increment with increasing concentrations of the drug, but even with $1 \%$ salbutamol it was significantly less than with $0.5 \%$ isoprenaline $(\mathrm{P}<0.05)$.

Time to Peak Effect on Heart Rate.-The time to peak effect was significantly longer after $0.5 \%$ salbutamol (25 minutes) than after $0.5 \%$ isoprenaline ( 7 minutes). There was no significant difference between the times to peak effect observed with the three concentrations of salbutamol.

Total Effect.-The total effect on heart rate of $0.5 \%$ isoprenaline was significantly greater $(\mathrm{P}<0.05)$ than that of $0.5 \%$ salbutamol. The total effect on heart rate of the three concentrations of salbutamol showed a statistically significant $(P<0.05)$ stepwise increment directly related to the concentrations used. There was no significant difference between the total effect on heart rate of $0.5 \%$ isoprenaline and $1 \%$ salbutamol.

Duration of Average Effect.-This was significantly related $(\mathrm{P}<0.05)$ to the concentration of salbutamol, but only after the highest concentration (1\%) was it significantly longer than after $0.5 \%$ isoprenaline.

Electrocardiographic Observations. - No cardiac dysrhythmia of any type was observed while either isoprenaline or salbutamol was being given or during the next 60 minutes.

\section{Effect of an Aerosol of Normal Saline}

In the six patients who received nebulized normal saline by IPPV there was no significant change in either $F_{1}$ or heart rate.

\section{Discussion}

The objectives of the study were to compare the bronchodilator activity and the effect on heart rate of (a) equal concentrations $(0.5 \%)$ of isoprenaline and salbutamol, each administered as an aerosol by IPPV, and (b) various concentrations of salbutamol $(0.25,0.5$, and $1 \%)$ administered by the same technique.

From the comparison of $0.5 \%$ isoprenaline with $0.5 \%$ salbutamol it was concluded (a) that these concentrations of isoprenaline and salbutamol were equipotent in respect of peak bronchodilator effect (maximum increase in $\mathrm{FEV}_{1}$ ), (b) that the time taken to attain peak bronchodilator effect was significantly shorter with isoprenaline, and $(c)$ that the total effect and the duration of average effect were significantly greater with salbutamol. On those criteria salbutamol has a distinct advantage over isoprenaline in terms of bronchodilator activity, except for its slightly less rapid action. It was also concluded (a) that isoprenaline had a significantly greater peak effect on heart rate than salbutamol, (b) that the peak effect was attained more rapidly, and (c) that the total effect was significantly greater. There was, however, no difference between the two drugs in the duration of average effect. In practical terms isoprenaline caused pronounced tachycardia of rapid onset, while salbutamol caused slight but more prolonged tachycardia.

From a comparison of the various concentrations of salbutamol it was concluded (a) that there was no significant difference between the peak bronchodilator effect of $0.25,0.5$, and $1 \%$ concentrations, (b) that there was no significant difference between the times taken to achieve peak bronchodilator effect, and (c) that the total effect and the duration of average effect were significantly related to the concentrations of salbutamol, but that in these respects even the lowest concentration $(0.25 \%)$ of salbutamol was more effective than $0.5 \%$ isoprenaline. On those criteria the highest concentration (1\%) of salbutamol had no advantage over the lowest $(0.25 \%)$ in terms of peak bronchodilator effect, but had a longer duration of action.

It was also concluded $(a)$ that the peak effect on heart rate was significantly related to the concentration of salbutamol, but that the peak increase in heart rate after even the highest dose $(1 \%)$ of salbutamol was significantly less than after $0.5 \%$ isoprenaline, and $(b)$ that the total effect and the duration of average effect after salbutamol were directly related in a stepwise manner to the concentrations used. The duration of average effect after $1 \%$ salbutamol (but not after the lower concentrations) was significantly longer than after $0.5 \%$ isoprenaline. In practical terms the tachycardia after salbutamol, in contrast with that observed after isoprenaline, was slight with all concentrations, and negligible with the two lowest concentrations $(0.25$ and $0.5 \%)$.

If an ideal bronchodilator drug is one which produces maximum bronchodilatation with minimum tachycardia, a $0.5 \%$ salbutamol aerosol administered by IPPV is manifestly superior to a $0.5 \%$ isoprenaline aerosol administered in the same way. The relative merits of $0.25,0.5$, and $1 \%$ salbutamol aerosols are more difficult to aesess. The peak bronchodilator effect of all three concentrations is similar. The slightly longer duration of action of the $1 \%$ concentration is offset by its slightly greater tendency to increase the heart rate, but the virtual absence of tachycardia with the $0.25 \%$ concentration is offset by its slightly shorter duration of action. It is therefore concluded that a $0.5 \%$ concentration represents a satisfactory compromise.

One of the main difficulties with studies of the type reported in this paper is the virtual impossibility of estimat- 
ing the dose of bronchodilator drug which reaches the bronchi. This problem was not of course resolved by the use of IPPV, which merely ensured that about the same volume of aerosol was delivered to the bronchi whatever drug or concentration was used. It is probable, however, that the average dose of isoprenaline received by the patients in this particular study was relatively large, because the increase in heart rate (29 per minute) produced by a $0.5 \%$ concentration given for three minutes by IPPV was much greater than that produced by $1,000 \mu \mathrm{g}$. of isoprenaline administered by pressurized dispenser (13 per minute) in a previous study reported by Choo-Kang et al. (1969) on a similar group of patients. The average dose of salbutamol received by the patients must have been equally large when a $0.5 \%$ concentration was used, but it caused a much smaller increase in heart rate.

IPPV has the capability, which a pressurized dispenser lacks, of delivering an adequate dose of bronchodilator aerosol to dyspnoeic patients. Such patients are often unable to inhale more than a small proportion of a single dose of aerosol from a pressurized dispenser, and this may partly account for the poor response of patients with status asthmaticus to bronchodilator drugs administered in that way. Furthermore, when the technique of IPPV is used, the drug is administered in a high concentration ( $40 \%$ or more) of oxygen, and if the studies in experimental animals with isoprenaline reported by Collins et al. (1969) are applicable to man this may reduce considerably the potential cardiotoxic hazards associated with the use of bronchodilator aerosols.

Though it cannot, of course, be assumed that a concentration of salbutamol which does not produce tachycardia is ipso facto less likely to provoke more serious cardiac side effects, it would seem reasonable, when powerful bronchodilatation is required, to select a form of treatment which does not increase the heart rate, and which at the same time ensures adequate oxygenation. These requirements can substantially be met by the administration of a $0.5 \%$ aerosol of salbutamol by IPPV in $40 \%$ oxygen for a period of three minutes.

The solutions of salbutamol and isoprenaline were supplied by Allen \& Hanburys Limited. We are indebted to Dr. D. Jack and Dr. W. T. Simpson for advice on the design of the trial, to Mrs. Barbara Dow for technical services, and to Mr. A. J. Davey for the statistical analysis.

REFERENCES

Choo-Kang, Y. F. J., Simpson, W. T., and Grant, I. W. B. (1969). British Medical fournal, 2, 287

Collins, J. M., McDevitt, D. G., Shanks, R. G., and Swanton, J. G. (1969) British fournal of Pharmacology, 36, 35

Hartley, D., Jack, D., Lunts, L. H. S., and Ritchie, A. C. (1968). Nature, 219, 861 .

Kennedy, M. C. S., and Simpson, W. T. (1969). British Fournal of Diseases of the Chest, 63, 165 .

Riding, W. D., Chatterjee, S. S., and Dinda, P. (1969). British Journal of Clinical Practice, 23, 217.

Warrell, D. A., et al. (1970). British Medical fournal, 1, 65.

\title{
Suppression of Ventricular Tachyarrhythmias by Transvenous Intracardiac Pacing after Acute Myocardial Infarction
}

\author{
M. A. BENNETT, ${ }^{*}$ M.R.C.P. ; B. L. PENTECOST, $\dagger$ M.D., M.R.C.P.
}

British Medical fournal, 1970, 4, 468-470

\begin{abstract}
ummary: Transvenous intracardiac pacing was carried $S$ out on nine patients with recurrent ventricular tachyarrhythmia after drug treatment had failed. In eight patients recurrent ventricular ectopic activity was suppressed by pacing at a rate above the sinus rate. With this technique the need for $D . C$. shock and repeated antiarrhythmic drugs can be avoided.
\end{abstract}

Recurrent ventricular tachycardia often terminating in fibrillation may be unavoidable after myocardial infarction in spite of prophylactic drug therapy. Such rhythm disturbances may be suppressed by rapid cardiac pacing, ${ }^{1-16}$ but this technique appears to have been little used after acute infarction. Pacing for recurrent ventricular tachyarrhythmia has been made relevant and feasible in many general hospitals with the widespread establishment of coronary care units, in which patients are closely supervised during the peak incidence of ventricular arrhythmias. Fluoroscopy facilities within the coronary care unit allow positioning of the transvenous pacing catheter without delay. This communication describes cardiac pacing in nine successive patients with recurrent ventricular tachyarrhythmia complicating acute myocardial infarction.

\section{Methods}

All nine patients were admitted to the hospital's coronary care unit. Before developing ventricular tachyarrhythmia they showed no evidence of cardiac failure, sinus bradycardia, or atrioventricular block; however, radiographic evidence of pulmonary oedema had developed in all nine at the time pacing was begun. The patients had not received a digitalis preparation and had normal serum electrolytes. Over 10 episodes of cardiac arrest were experienced by each patient (Table I). The

* Research Fellow.

t Consultant Physician.

Coronary Care Unit, General Hospital, Birmingham 4. term "cardiac arrest" is used here to indicate impairment of consciousness secondary to ventricular tachyarrhythmia which did not spontaneously revert to sinus rhythm.

After the initial episode of arrest the patients received prophylactic lignocaine by continuous infusion; additional chemotherapy was given if this failed to suppress ventricular ectopic activity (Table II). All episodes of prolonged ventricular tachycardia or ventricular fibrillation were terminated by D.C. shock. Pacing was started when drug therapy was considered to have failed; lack of definition of this failure point resulted in a variable delay before pacing. A transvenous bipolar catheter (6F U.S.C.I.) and a fixed-rate pacemaker (Medical Electronics and Instruments, Birmingham) were used. The catheter was introduced into a medial arm vein at

\begin{tabular}{|c|c|c|c|c|c|c|}
\hline Case No. & & & Sex & Age & Infarction Site & No. of Arrests \\
\hline $\begin{array}{l}1 \\
2 \\
3 \\
4 \\
5 \\
6 \\
7 \\
8 \\
9\end{array}$ & $\begin{array}{l}\ldots \\
\cdots \\
\cdots \\
\cdots \\
\cdots \\
\cdots\end{array}$ & $\begin{array}{l}\ldots \\
\cdots \\
\cdots \\
\cdots \\
\cdots \\
\cdots \\
\cdots\end{array}$ & $\begin{array}{l}\text { M. } \\
M . \\
M . \\
F . \\
F . \\
M . \\
F . \\
M . \\
M .\end{array}$ & $\begin{array}{l}55 \\
42 \\
51 \\
48 \\
62 \\
47 \\
52 \\
57 \\
64\end{array}$ & $\begin{array}{l}\text { Anterior } \\
\text { Anterior } \\
\text { Anterior } \\
\text { Inferior } \\
\text { Anterior } \\
\text { Anterior } \\
\text { Anterior } \\
\text { Inferior } \\
\text { Inferior }\end{array}$ & $\begin{array}{l}28 \\
29 \\
24 \\
18 \\
22 \\
11 \\
27 \\
14 \\
19\end{array}$ \\
\hline
\end{tabular}

TABLF II.-Drug Therapy and its Duration of Administration Prepacing

\begin{tabular}{|c|c|c|c|c|}
\hline Case No. & & Lignocaine (mg.) & Procainamide (mg.) & Quinidine (mg.) \\
\hline $\begin{array}{l}1 \\
2 \\
3 \\
4 \\
5 \\
6 \\
7 \\
8 \\
9\end{array}$ & \begin{tabular}{l|}
$\cdots$ \\
$\cdots$ \\
$\cdots$ \\
$\cdots$ \\
$\cdots$ \\
$\cdots$ \\
$\cdots$ \\
$\cdots$
\end{tabular} & 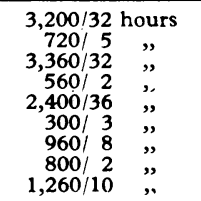 & 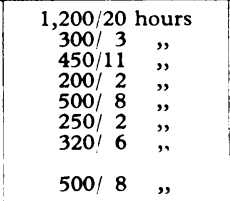 & $\begin{array}{l}500 / 8 \text { hours } \\
1,500 / 35,\end{array}$ \\
\hline
\end{tabular}

